\title{
Septal lesions and aggressiveness in the cotton rat, Sigmodon hispidus'
}

B. N. BUNNELL AND M. H. SMITH?

UNIVERSITY OF FLORIDA
Septal lesions resulted in a significant increase in the number of interanimal contacts made by cotton rats, but produced no consistent increase in social rank. Thresholds for both attack and escape responses were lower and these responses were poorly timed and directed. The data are consistent with a disinhibition hypothesis of septal lesion effects.

Previous work on the effects of septal lesions on social dominance (Bunnell et al, 1966) left some doubt as to the generality of the findings. While it appeared that the social behavior of hooded rats was changed by these lesions, it was possible that the observed increase in dominance was an artifact of the apparatus and procedures used to assess social rank. To examine the generality of septal effects on social behavior, septal lesions were given to cotton rats (Sigmodon hispidus) and their behavior observed in a seminatural environment.

\section{Subjects and Apparatus.}

A large number of cotton rats were trapped locally and, from among these, 24 adult males, ranging in weight from 85 to $182 \mathrm{gm}$ were selected. Two groups of four and two groups of eight were formed such that each group contained Ss whose weights spanned the available range. Pelage marking was used for identification. Ss were housed in seminatural environment cages $3 \mathrm{ft}$. wide, $4 \mathrm{ft}$. deep, and $5 \mathrm{ft}$. high (see Bunnell, 1966). A normal $12 \mathrm{hr}$. light dark cycle was maintained using $15 \mathrm{w}$ bulbs. Another circuit, using $100 \mathrm{w}$ bulbs, was used to signal the availability of water.

\section{Procedure}

Ss were placed on an 11-hr. water deprivation schedule, with water availability coinciding with the observation periods. Observations were made between 7-8 a.m. and 7-8 p.m. daily. An observation period was initiated by turning on the bright lights and attaching a water bottle to the front of each cage. Ss readily learned to emerge from the nest boxes in response to the light cue.

Three behavioral scores were obtained: (1) Frequency of interactions; (2) Number of wins and losses, and (3) Aggressiveness, in which each interaction was rated according to a modified version of the Klein-Hall (Hall \& Klein, 1942). Social dominance rank was determined from the win-loss scores each $\mathrm{S}$ made against every other animal in its group. An $\mathrm{S}$ was said to be dominant over another if it won at least $75 \%$ of its encounters with that animal.

Five observers were trained during preliminary observations of the groups until satisfactory (upward of $95 \%$ agreement) reliability was achieved. Normally, one observer scored two groups during an observation period. Twenty observation periods were then scheduled and the results used to determine the dominance order within each group. The lowest ranking animal in each group was then given a septal lesion, while the animal in the next to lowest position was given a control operation.

All Ss were given ad lib water beginning $24 \mathrm{hr}$. prior to surgery. The Ss receiving the operations were individually housed for $24 \mathrm{hr}$. preoperatively and 46 hr. postoperatively, after which they were returned to the group cages. Water deprivation was resumed $24 \mathrm{hr}$. postoperatively. In two of the groups, postoperative testing followed the schedule used preoperatively, and was continued for five days. In the other two groups, extra observations were made during times when water was not available in order to give extended coverage of postoperative behavior. These two groups were observed until the social structure of the group restabilized, then another $\mathrm{S}$ was given a septal lesion, and a second series of postoperative observations were made. This process was repeated yet again in one group. In all, data were obtained on seven septals and four operated controls.

Bilateral septal lesions were made by electrocoagulation under Nembutal. In the control operations, the electrode was lowered only as far as the corpus callosum and no current was passed. After testing, the animals were sacrificed and standard histological procedures used for lesion reconstruction. ${ }^{3}$

\section{Results and Discussion}

1. Preoperatively, savage fighting occurred shortly after the groups were formed. Six animals were killed, two in each of the larger groups and one in each of the smaller groups. Cotton rats did not appear to have any submissive postures which could serve to terminate the aggression of an attacker, but relied on escape behavior to avoid injury. The typical attack was directed at the neck and upper back of the opponent, and was followed by biting and tumbling until one animal broke loose and fled. The winner usually chased the loser and repeated its attacks several times.

Stable dominance-subordination relationships and transitive dominance hierarchies appeared in each group prior to surgery. There was no consistent relationship between body weight and either aggressiveness or social rank.

2. The frequency of interactions increased significantly in septal Ss. Preoperatively the mean number 
Table 1. Pre- and Postoperative Social Dominance Ranks and Percent of Interactions Won, Tied, and Lost for Seven Septal Animals

\begin{tabular}{rllllllll}
\multicolumn{1}{l}{$\begin{array}{l}\text { S } \\
\#\end{array}$} & \multicolumn{3}{c}{$\begin{array}{c}\text { Social Ronk } \\
\text { Preop Postop }\end{array}$} & \multicolumn{3}{c}{ Preop (\%) } & \multicolumn{3}{c}{ Postop (\%) } \\
\hline 201 & $5 / 5$ & $1 / 5$ & .14 & .49 & .37 & .74 & .09 & .17 \\
31 & $3 / 3$ & $2 / 3$ & .02 & .88 & .10 & .46 & .21 & .33 \\
62 & $6 / 6$ & $4 / 6^{*}$ & .09 & .21 & .71 & .29 & .21 & .50 \\
202 & $2 / 3$ & $1 / 3$ & .32 & .35 & .33 & .55 & .45 & .00 \\
42 & $4 / 4$ & $4 / 4^{*}$ & .17 & .14 & .69 & .05 & .13 & .82 \\
22 & $2 / 2$ & $2 / 2$ & .08 & .21 & .71 & .05 & .05 & .90 \\
32 & $1 / 3$ & $3 / 3^{*}$ & .93 & .05 & .02 & .06 & .00 & .94 \\
\hline
\end{tabular}

* killed by other animals

of interactions per opponent per observation period (I/O/O score) was .91 ; postoperatively, it rose to $2.31(t=2.80, \mathrm{df}=6, \mathrm{p}<.05)$.

A smaller, but consistent, increase in interanimal contacts was also found in the operated controls. Their preoperative $\mathrm{I} / \mathrm{O} / \mathrm{O}$ mean was .89 ; this rose to 1.71 after they were returned to the group cages $(t=2.34$, $\mathrm{df}=3, .10>\mathrm{p}>.05$ ). Most of this increase was due to increased contact with the septals. Operated controls continued to avoid animals other than the septals (over which they had been dominant prior to surgery).

The preoperative mean I/O/O score for nonoperated controls was 1.47 , postoperatively it was 1.13 . This difference was not significant, and the decrease was not consistent. These Ss had fewer interactions with other controls and more with septals. The net effect was a slight increase in the two smaller groups and a decrease in the two larger groups.

3. Table 1 summarizes the pre- and postoperative dominance rankings and the win-tie-loss scores for the seven septal Ss. Overall, the septals showed an increase of $17 \%$ in the number of decisive interactions which they won, but the lesions did not produce a consistent increase in either dominance rank or in the ability to win aggressive encounters and three of the seven septals were eventually killed.

Operated controls did not show any changes in postoperative rank or in wins and losses with respect to the nonoperated controls. In three out of four cases they were consistently beaten by septals, in the fourth case, only one interaction (won by the septal) was observed before the septal was killed by a dominant normal control.

4. Septals repeatedly approached other animals and would occasionally jump on their backs in the characteristic attack used by this species. However, they broke off their attacks immediately, and were never observed to bite. This is reflected in the aggressiveness rating scores of those septals which increased in dominance. They showed a modest increase in aggression, but never received scores in the three highest categories of the rating scale. Such scores were common among dominant normals.

When the abortive attack by a septal caused an opponent to flee, the interaction terminated and the septal switched to some other activity such as grooming, exploring, eating, or drinking. When the other animal fought back, the septal typically broke off the attack and fled. The fleeing behavior was abnormal both in its high intensity and in its poor direction. The septal ran around and around the cage, frequently stopping a few inches from the animal that had just defeated it. If the other animal did not then renew the attack, the septal usually approached it again despite the fact that the septal might have been wounded by the same animal only a few moments before.

In summary, the main characteristics of the septal behavior were the persistent approaches to other animals, an apparent lowering of the threshold for both aggressive and escape responses, and the poor timing and direction of these responses. The results are consistent with disinhibition theories of septal lesion effects (e.g., Kaada et al, 1962) and suggest that the increase in social status in the septal laboratory rat obtained by Bunnell et al (1966) was a function of the testing conditions which were used.

\section{References}

Bunnell, B. N. Amygdaloid lesions and social dominance in the hooded rat. Psychon. Sci., 1966, 6, 93-94.

Bunnell, B. N., Bemporad, J. R., \& Flesher, Carol k. Septal forebrain lesions and social dominance in the hooded rat. Psychon. Sci., 1966, 6, 207-208.

Hall, C. S., \& Klein, S. J. Individual differences in aggressiveness in rats. J. comp. Psychol., 1941, 33, 371-383.

Kaada, B. R., Rasmussen, E. W., \& Kveim, O. Impaired acquisition of passive avoidance behavior by subcallosal, septal, hypothalamic, and insular lesions in rats. J. comp. physiol. Psychol., 1962, 55, 661-670.

\section{Notes}

1. This work was supported by Grants 18646 and B1149 from the National Science Foundation. The authors are indebted to J.Dowler, $\mathrm{J}$. Kramer, and C. Wells for assistance in making the behavioral observations.

2. Now at University of Georgia Institute of Ecology.

3. Copies of the lesion reconstructions may be obtained from B. N. Bunnell. 